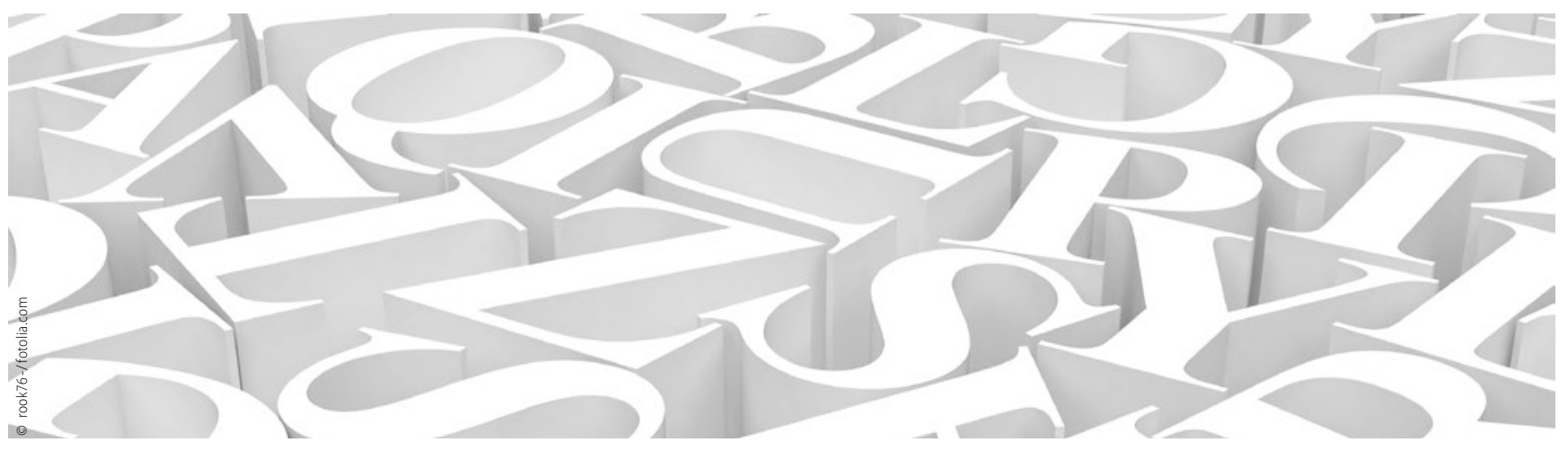

Buchhaltungs- $A B C$

\title{
A - wie Anfangsbestände ermitteln und buchen
}

Zum Beginn eines neuen Wirtschaftsjahres müssen in der Buchhaltung vorbereitende Buchungen durchgeführt werden. Dazu gilt es, einiges zu beachten, da die Konten unterschiedlich gehandhabt werden müssen.

Bei den Bestandskonten (Anlagevermögen, Darlehen sowie Finanz- und Interimskonten) müssen die Endbestände des Vorjahres (31.12.) zum Jahresstart (01.01.) vorgetragen werden. Dies ist bei den sogenannten Erfolgskonten (beispielsweise KZV-Einnahmen, Miete, Porto) nicht erforderlich, da sie in jedem Jahr neu mit „Null“ beginnen.

\section{Anfangsbestand der Finanzkonten}

Finanzkonten (Kasse, Bank) haben am Ende des Jahres in der Regel einen Bestand, der bei der Kasse immer positiv ist, bei Bankkonten jedoch auch negativ, also in der Überziehung, sein kann. Um nach jeder Buchungssitzung den Saldo zum letzten Buchungstag kontrollieren zu können, muss der Anfangsbestand eingebucht werden. Ein Guthaben-Bestand wird im Soll eingebucht, Überziehung im Haben.

Der Buchungssatz für ein Guthaben wäre also zum Beispiel

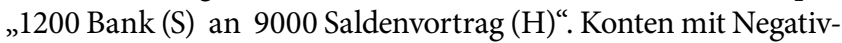
Saldo wären mit „9000 Saldenvortrag (S) an 1200 Bank $(\mathrm{H}) “ \mathrm{zu}$ bebuchen. (Alle hier verwendeten Konten entsprechen dem SKR03.)

\section{Anfangsbestände Anlagegüter}

Die Saldenvorträge der Anlagekonten können dem Jahresabschluss oder dem Anlagespiegel des Vorjahres entnommen werden. Es ist jedoch möglich, die Verbuchung dieser Saldenvorträge im Zuständigkeitsbereich des Steuerbüros zu lassen, da sie weder für die unterjährige Buchung noch für die Aussagekraft der BWA und der Liquiditätsrechnung von Bedeutung sind.

\section{Anfangsbestände Darlehen}

Die Saldenvorträge der Darlehenskonten findet man im Jahresabschluss oder den Darlehenskontoauszügen des Vorjahres. Auch hier ist es nicht zwingend notwendig, die Anfangsbestän- de am Jahresanfang einzubuchen, aber es hat den Vorteil, dass man den aktuellen Darlehensstand in der Liquiditätsrechnung leichter im Auge behalten kann.

Achtung: Die Jahresanfangsbuchungen sind in fibu-doc bereits hinterlegt, so dass man nur noch die Beträge einsetzen muss.

Nächster Tipp: A - Abschreibung

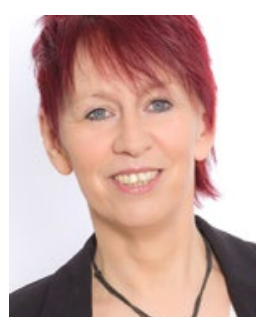

Barbara Mertens

www.fibu-doc.de

Mehr Infos unter www.fibu-doc.de

Das in den Artikeln dargestellte Buchhaltungskonzept basiert auf der zahnarztspezifischen Buchhaltungssoftware fibu-doc und wird vom FVDZ unterstützt.

\section{Seminare:}

Praxiskennzahlen: Verstehen - vergleichen - verbessern 11.09.2015 - Stuttgart

Personalkosten: Kennen - gestalten - kontrollieren

18.09.2015 - München

11.11.2015 - Frankfurt 